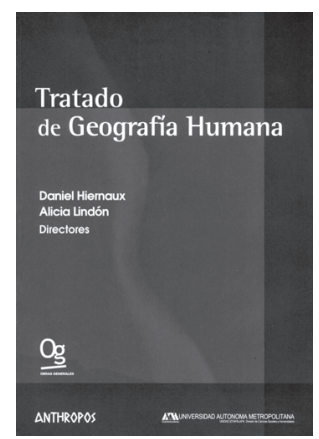

\title{
Daniel Hiernaux y Alicia Lindón (Directores). Tratado de Geografía Humana
}

\author{
Editorial Antrophos; México, 2006, 652 p.
}

\author{
Macarena Pérez ${ }^{1}$
}

El Tratado de Geografía Humana que se presenta en esta ocasión tiene como eje principal la integración de distintas perspectivas de la Geografía expuestas por cada uno de los autores, orientándose a la realidad iberoamericana, y al análisis de fenómenos propios de los países que la componen. El desafío para los autores, más allá de la profundización en cada uno de los temas que se exponen, es la confrontación con la realidad cambiante propia del Tercer Milenio. Como respuesta a esta situación se plantea una revisión necesaria a la disciplina geográfica y al espacio como objeto de estudio central, no solo de la geografía sino que también de disciplinas auxiliares.

A partir de esto, se plantea por los autores al momento de revisar la Geografía Humana, como imposible excluir del enfoque de análisis las disciplinas que permiten el estudio del espacio geográfico, siendo este espacio el que en el mundo contemporáneo se presenta como centro de estudio, y que debido a su complejidad requiere de acercamientos interdisciplinarios. Los autores expresan la relevancia de construir un nuevo marco teórico para el análisis del espacio basado en el diálogo con otras ciencias sociales.

Por medio de la incorporación de un capítulo destinado a los campos emergentes de la Geografía, se pretende dar cabida no solo a los desafíos de la Geografía postmoderna, es decir, involucrarse en discusiones filosóficas y metodológicas, sino que también dar espacio al trabajo con metodologías cualitativas. La reorientación o "cambios de giro" dados a la Geografía postmoderna se aprecian en varios capítulos del libro, no siempre con claridad, pero referidos a través del tratamiento de temáticas particulares a la valorización del individuo en el contexto en que se inserta.

Entre los cuestionamientos que plantean los autores como necesarios para abordar el estudio de la Geografía en un contexto actual y teniendo en consideración que en esta obra se abordan temas de la Geografía contemporánea más reciente, específicamente a partir de 1970, surgen interrogantes referidas a la Geografía Humana, y el cómo esta responde a la validez de ciertos campos que la componen.

El Tratado de Geografía Humana reconoce tener como tradiciones constitutivas la fuente anglosajona y francófona, pero plantea como tercera tradición la iberoamericana. Esta tradición expresa una hibridación intelectual entre las fuentes mencionadas que se acerca a la realidad de Iberoamérica.

El libro se estructura diferenciando por una parte los campos tradicionales de la Geografía Humana y los emergentes, tomando en consideración que no siempre los pertenecientes al segundo tipo son completamente independientes de los tradicionales, sino que están insertos en estos, y que de la misma forma los Ilamados tradicionales no están completamente apegados a ideas más antiguas.

\footnotetext{
1 Licenciada en Geografía, Pontificia Universidad Católica de Chile (Chile).E-mail: mperez1@uc.cl
} 
Entre las ramas consideradas por los autores como tradicionales se mencionan en el texto la Geografía Económica, Geografía de la población, Geografías Históricas y Fronteras, Geografía y Geopolítica, Geografía Política, Geografía Cultural, Geografía y Paisaje.

Los campos tradicionales considerados en el tratado, abarcan la Geografía Regional, la Geografía Rural, y especial énfasis en la Geografía Urbana, cuyo análisis se trata en detalle en un capítulo que la aborda desde la mirada de América Latina. La importancia dada en el libro a esta rama de la Geografía radica en primer lugar a la tendencia creciente hacia la urbanización en el mundo, y en segunda instancia a la relevancia del fenómeno urbano expresado bajo distintas formas en América Latina. Entre las principales temáticas abordadas por investigadores latinoamericanos se encuentra el estudio de las ciudades intermedias, los barrios cerrados y ciudades amuralladas, y los procesos de suburbanización y gentrificación.

De especial interés resulta el campo abarcado en el capítulo de Geografía y Paisaje, que traspasa las barreras de la Geografía Humana, considerando el espacio como un sistema, y por lo tanto que debe ser analizado tomando en cuenta la Geografía Física como parte del paisaje. En este capítulo se hace referencia a la importancia de considerar el paisaje como aporte para análisis de problemas medioambientales, y como punto de encuentro interdisciplinario entre las ciencias humanas y la geografía física. Este enfoque es, sin duda, innovador y trascendental para el desarrollo del argumento de este capítulo de la obra. Los autores plantean la idea acerca de la limitación que ha sufrido la Geografía Física al no considerar aspectos como las relaciones humanas, y que ha impedido la participación de geógrafos en discusiones referidas al medio ambiente. Esta situación de quiebre entre las ramas humana y física de la Geografía se aborda en los años setenta, planteando como esencial la existencia de una geografía más integrada que tenga especial consideración en planteamientos medioambientales aplicados a las dos geografías, hecho que en la realidad actual resulta clave, al momento de realizar análisis integrados, tal como lo requiere para su estudio el territorio y el espacio geográfico.

El concepto de paisaje resulta entonces poseedor de distintas acepciones, considerando entre estas la expresión artística de la realidad y la construcción intelectual del paisaje. La comprensión geográfica del paisaje tiene su origen en el edafólogo ruso V.V. Dokuchaiev, a finales del siglo XIX, y establece el principio del análisis integral del territorio. Esta concepción del territorio es producto del cuestionamiento sobre el papel del suelo en los sistemas territoriales, orientando la Geografía al análisis sintético del medio geográfico, es decir considerando factores de distinta índole que interactúan en el espacio.

Esta concepción inicial del paisaje desde la perspectiva geográfica se ve distanciada de su objeto inicial, por estudios en ámbitos como los paisajes culturales, que rompen a menudo con los elementos "naturales" del paisaje. Solo en las últimas décadas del siglo XX se retoma la aproximación del paisaje-objeto al paisaje-sujeto, entrando en una etapa de redescubrimiento emprendida por la Geografía Física, tanto de los temas más integrados como de la dimensión cultural de la relación hombre-medio ambiente.

Durante la segunda mitad del siglo XX, la investigación físico-geográfica se vuelca hacia la integración a través de la introducción de la Teoría de Sistemas en las investigaciones geográficas, dando respuesta de esta forma a los nuevos problemas medioambientales y a la ordenación del territorio.

Es en Rusia donde se da mayor importancia a la renovación conceptual del análisis integrado del medio físico, introduciendo la idea de geosistema, como sistema de elementos naturales localizado en el espacio. Por medio de esta concepción se pretende dar una visión de la Geografía Física con la capacidad de explorar la relación entre lo natural y lo social.

En busca de esta visión se trata por los autores el sistema metodológico propuesto en los años noventa por Cl. y G. Bertrand, fundado sobre tres conceptos espacio-temporales: geosistema, territorio y paisaje 
(GTP). Entre las características principales de los subsistemas del GTP, se entiende al geosistema, como un concepto que trata el medio ambiente como "fuente", que permite analizar un espacio geográfico tal y como funciona, con el grado de antropización que posea. El concepto de territorio trata al espacio geográfico como "recurso" y permite basándose en los procesos de artificialización del medio ambiente, analizar las repercusiones de la organización, funcionamiento social y económico sobre el espacio. El paisaje en tanto se considera como "entrada" sociocultural en el sistema ambiental. Esta metodología permitiría el acoger como parte del estudio de la geografía física lo referente al ser humano, incorporado a través de su situación en el paisaje, poniendo fin a la divergencia entre ramas de estudio.

Los capítulos pertenecientes al apartado de campos emergentes se refieren a ciertos temas actuales abordados por los estudios geográficos y corresponden a: Geografía y Mundialización, que abarca los temas de globalización; Geografía y desarrollo local; Geografía y Consumo; Geografía del Género; Geografía del Turismo; Espacio y Lenguaje; Geografía y literatura; Geografía de las religiones; Geografía y Violencia urbana; Geografía y ciberespacio; Geografías de la vida cotidiana.

Especial interés despierta el capítulo referido a la Geografía y Ciberespacio, que plantea la imagen de la sociedad contemporánea volcada hacia los interiores, hacia los espacios cerrados y hacia actividades que nos alejan de la calle y espacios comunes, dando la posibilidad de experimentar en una dimensión construida a partir de la tecnología. Este desarrollo tecnológico ha permitido la conformación de un espacio, vinculado directamente a la sociedad posmoderna, que se relaciona en variadas áreas a través de la informática, acercando espacios lejanos, personas y fronteras que se ven superadas como resultados de los procesos en que se recrea la realidad. Este proceso se ha llamado hiperrealidad, y consiste en la creación de modelos que no se crean en la realidad misma, pero que son vividos como tales. El ciberespacio es reflejo de una simulación que no tiene relación con una realidad material, es imaginario y es Ilama- do por la autora como ecos de la cuarta dimensión.

El ser humano ha creado territorios y regiones virtuales a través de la tecnología, produciendo conexiones y relaciones cibernéticas que tienen sustento físico en computadoras, cables, circuitos electrónicos, redes telefónicas, entre otros. Se plantea el ciberespacio como sustento de una dimensión superior, poseedora de habitantes, lugares y relaciones que hacen que la distancia lineal por ejemplo entre dos personas pierda importancia, y se encuentre normada por leyes propias de esta cuarta dimensión. Esta dimensión superior virtual es generada con la tecnología, y se reconocen dos manifestaciones del ciberespacio dominantes: la realidad virtual e Internet. Ambas nos llevan a conformar paisajes virtuales y a la creación de relaciones sociales a través de conexiones cibernéticas, generando un espacio alternativo habitado por seres de carne y hueso, seres cibernéticos, parcialmente electrónicos y por otros que pertenecen al mundo de la imaginación, y son reconocidos como un alter ego de los navegantes de la red.

La realidad virtual, expuesta por la autora, no es más que una imitación de lo real, construido a partir de una programación previa generada por un modelo computacional. Hasta ahora esta realidad virtual suele limitarse a la simulación de lugares concretos, imitando características del espacio tridimensional.

Una segunda manifestación del ciberespacio corresponde a Internet, como una red de intercambio de información, hoy en día masiva y que permite no solo las relaciones empresariales y comerciales, como se postuló en sus inicios, sino que actúa como una posibilidad de comunicación y espacio para la generación de comunidades conformadas por cyborgs, o habitantes del ciberespacio, expresión de la tecnologización de lo humano.

Surge la interrogante frente a esta realidad creadora del ciberespacio, con respecto al rol de la Geografía Humana en el estudio de este medio tecnológico. La respuesta a esto está dada por la reubicación de las re- 
laciones sociales, siendo la cibergeografía presentada como el estudio de la naturaleza espacial de las actuales redes de comunicación y los espacios existentes entre las pantallas de las computadoras. Entre los ámbitos de estudio se incluye la distribución espacial de las infraestructuras físicas de comunicación, y la percepción humana de los nuevos espacios digitales.

Desde la Geografía, el ciberespacio es un ámbito de estudio reciente, pero que a partir de las nuevas estructuras espaciales generadas en la vida social, económica, política y cultural ha abierto un ámbito de estudio de la llamada cuarta dimensión.

Un último capítulo hace referencia al ejercicio profesional del geógrafo, considerando la Geografía y Cartografía, la Geografía y Sistemas de Información Geográfica, la Geografía y el Ordenamiento Territorial y por último la Enseñanza de la Geografía, a nivel de enseñanza secundaria.

Presenta un especial interés el capítulo referido a la Geografía y Sistemas de Información Geográfica, esto debido al contexto actual en que se desenvuelve la Geografía, incorporando la utilización de herramientas informáticas a los estudios. Se destaca la importancia de la utilización de estas herramientas para el análisis espacial de fenómenos de distinta índole, debiendo tener bases conceptuales sólidas para la consistencia de los análisis. Solo dando relevancia a las bases geográficas que sustentan el trabajo con herramientas informáticas se estará otorgando valor al privilegio de la Geografía al poseer un lugar preferencial en la evolución de las tecnologías.

\section{Comentario Final}

El Tratado de Geografía Humana permite un acercamiento a los distintos ámbitos de la Geografía actual, siendo una obra innovadora que incorpora una visión multidisciplinaria como respuesta al giro cultural experimentado por la Geografía, que al igual que otras disciplinas ha debido replantearse frente a las problemáticas modernas.

Sin duda este libro ha logrado plasmar la visión particular de cada uno de los autores que lo componen y por sobre todo realiza un aporte desde la visión Iberoamericana en la forma de entender la Geografía actual, capaz de adaptarse a los tiempos y requerimientos de la sociedad. Se responde de esta forma a la inquietud siempre presente referida a la posición y el papel de la Geografía frente a las temáticas que afectan directamente la vida cotidiana, confirmando la riqueza de la ciencia geográfica como poseedora de herramientas y conocimientos que permiten la espacialización de fenómenos y análisis a distintas escalas. 